\title{
The influence of in situ argon cleaning of GaAs on Schottky diodes and metal-semiconductor field-effect transistors
}

\section{Citation for published version (APA):}

Hassel, van, J. G., Heyker, H. C., \& Kwaspen, J. J. M. (1995). The influence of in situ argon cleaning of GaAs on Schottky diodes and metal-semiconductor field-effect transistors. Journal of Vacuum Science and Technology, $B, 13,2245-2249$. https://doi.org/10.1116/1.588057

DOI:

10.1116/1.588057

Document status and date:

Published: 01/01/1995

\section{Document Version:}

Publisher's PDF, also known as Version of Record (includes final page, issue and volume numbers)

\section{Please check the document version of this publication:}

- A submitted manuscript is the version of the article upon submission and before peer-review. There can be important differences between the submitted version and the official published version of record. People interested in the research are advised to contact the author for the final version of the publication, or visit the $\mathrm{DOI}$ to the publisher's website.

- The final author version and the galley proof are versions of the publication after peer review.

- The final published version features the final layout of the paper including the volume, issue and page numbers.

Link to publication

\section{General rights}

Copyright and moral rights for the publications made accessible in the public portal are retained by the authors and/or other copyright owners and it is a condition of accessing publications that users recognise and abide by the legal requirements associated with these rights.

- Users may download and print one copy of any publication from the public portal for the purpose of private study or research.

- You may not further distribute the material or use it for any profit-making activity or commercial gain

- You may freely distribute the URL identifying the publication in the public portal.

If the publication is distributed under the terms of Article 25fa of the Dutch Copyright Act, indicated by the "Taverne" license above, please follow below link for the End User Agreement:

www.tue.nl/taverne

Take down policy

If you believe that this document breaches copyright please contact us at:

openaccess@tue.nl

providing details and we will investigate your claim. 


\title{
Influence of in situ argon cleaning of GaAs on Schottky diodes and metal-semiconductor field-effect transistors
}

\author{
J. G. van Hassel, H. C. Heyker, and J. J. M. Kwaspen \\ COBRA Interuniversity Research Institute on Communication Technology, Department of Electrical \\ Engineering, Eindhoven University of Technology, NL-5600 MB Eindhoven, The Netherlands
}

(Received 27 March 1995; accepted 23 September 1995)

\begin{abstract}
The influence of in situ argon cleaning of GaAs on the electrical characteristics of Schottky diodes and metal-semiconductor field-effect transistors (MESFETs) is investigated. The beam energy was varied from 50 to $500 \mathrm{eV}$ and the characteristics were compared to wet chemically cleaned devices. The characteristics of the Schottky diodes showed a significant degradation as a consequence of damage introduced by argon cleaning. Recovery was obtained with an additional annealing step at $300{ }^{\circ} \mathrm{C}$ for diodes cleaned at energies below $125 \mathrm{eV}$. For higher energies, the samples became worse with annealing. MESFETs showed degraded performances for positive gate voltages due to a high gate leakage current. Improvement was also obtained upon annealing. () 1995 American Vacuum Society.
\end{abstract}

\section{INTRODUCTION}

Ion milling (or etching) can be used for pattern transfer or in situ cleaning before an evaporation. During the milling process atoms are removed mechanically from the target. This is performed by bombardment with ions or neutral atoms with a certain energy. However, it is desirable that minimal crystal damage be introduced by this bombardment. This can be best realized with ions/atoms having lowbombardment energy.

Much research has been done on the damage introduced in GaAs by ion milling. This damage has been analyzed by many different techniques like transmission electron microscopy (TEM), ${ }^{1}$ deep-level transient spectroscopy (DLTS), ${ }^{2-4}$ channeling Rutherford backscattering spectrometry (RBS), ${ }^{5}$ photoluminescence (PL), ${ }^{6}$ and electrical characterization of electronic components. ${ }^{6-10}$ With the last technique, mainly Schottky diodes are evaluated by $I-V$ and $C-V$ measurements. Generally, a strong degradation is observed in the electrical characteristics of Schottky diodes, although little is reported on the influence of argon cleaning on the behavior of MESFETs.

There is little known from literature about the projected range of the damage. The damage is often related to point defects, such as vacancies or interstitials, which can extend to a high degree of crystal disorder. The extension of the damage observed in GaAs ranges between less than 10-100 $\mathrm{nm}$. ${ }^{1,6,9,11,12}$ Although it is clear that the near-surface region is strongly disordered, some damage extends deeper into the material. The amount of damage also depends on the mass of the ions/atoms used. ${ }^{6,12}$ Heavy ions like xenon have a smaller penetration depth and produce less damage than light atoms like neon or helium. Reduction of the damage is also obtained by adding a reactive gas like chlorine $\left(\mathrm{Cl}_{2}\right)$ near to the sample. ${ }^{6}$

In this work, the influence of in situ etching/cleaning with neutral argon species with low energy is investigated on GaAs Schottky diodes and metal-semiconductor field-effect transistors (MESFETs), which are fabricated simultaneously.
After a short description of the ion source, the results of the electrical characterization and the influence of annealing will be presented.

\section{EXPERIMENT}

The ion source is dedicated to prepare a clean semiconductor surface to remove residual oxide or contamination from the surface. The plasma of the ion gun, a Leybold IQ70, is maintained in a quartz cylinder. This cylinder is surrounded by a radio-frequency (rf) induction coil. The rf power is supplied at a frequency of $13.56 \mathrm{MHz}$ and the power ranges up to $700 \mathrm{~W}$. Matching of the reflected rf power is done automatically. The Ar ions are extracted from the plasma by three molybdenum grids. The first grid, which is nearest to the plasma, is additionally coated with aluminium oxide to prevent contamination sputtered from the grid. The first grid (positively biased) determines the energy of the ions. This energy can be varied between 50 and 2000 $\mathrm{eV}$. Between the first and second grid (negatively biased) the ions are accelerated. The third grid (earth) is needed to set the energy of the ions back to their initial value of the first grid. Above the grids is a tungsten filament to neutralize the beam. The beam diameter is $70 \mathrm{~mm}$. The ion current can be measured with a Faraday cup located between the ion gun and the target.

During the experiments an argon flow of $4 \mathrm{sccm}$, a chamber pressure of $1.8 \times 10^{-4} \mathrm{mbar}$, and a rf power of $270 \mathrm{~W}$ was used. Table I lists the extracted current densities and the normalized etch rates on GaAs at different argon energies. The etch rates are normalized to the extracted current density. These etch rates appear to be consistent with previously reported values. 1,5

The experiments on the diodes and MESFETs are performed on a structure grown by molecular beam epitaxy (MBE) which consists of a $2 \mu \mathrm{m}$ undoped GaAs buffer layer, a $200 \mathrm{~nm}(\mathrm{Si}) n$-GaAs $\left(3 \times 10^{17} \mathrm{~cm}^{-2}\right)$ active layer, and a 20 $\mathrm{nm} n^{+}$-GaAs $\left(2 \times 10^{18} \mathrm{~cm}^{-2}\right)$ top layer grown on a semiinsulating substrate. After defining the mesa $\mathrm{Ge} / \mathrm{Ni} / \mathrm{Au}$, ohmic contacts are evaporated and annealed and the resist is patterned for the diodes $\left(200 \times 200 \mu \mathrm{m}^{2}\right)$. The diodes are 
TABLE I. The dependence of the current density and the normalized etch rate of GaAs on the ion energy.

\begin{tabular}{ccc}
\hline \hline $\begin{array}{c}\text { Energy } \\
(\mathrm{eV})\end{array}$ & $\begin{array}{c}\text { Current density } \\
\left(\mathrm{mA} / \mathrm{cm}^{-2}\right)\end{array}$ & $\begin{array}{c}\text { Normalized etch rate } \\
\left(\mathrm{nm} \mathrm{s}^{-1} \mathrm{~mA}^{-1} \mathrm{~cm}^{-2}\right)\end{array}$ \\
\hline 50 & 0.62 & 1.1 \\
125 & 0.81 & 1.2 \\
250 & 0.99 & 1.8 \\
500 & 1.17 & 2.3 \\
750 & 1.25 & 2.9 \\
\hline \hline
\end{tabular}

surrounded by the ohmic contact. Subsequently, the GaAs top layer is removed wet chemically in a diluted ammoniahydrogenperoxide $\left(\mathrm{NH}_{4} \mathrm{OH}: \mathrm{H}_{2} \mathrm{O}_{2}: \mathrm{H}_{2} \mathrm{O}\right)$ solution at room temperature. Before loading the sample in the evaporator, the GaAs surface is cleaned in diluted ammonia to remove any residual oxide from the surface. In the evaporator the GaAs surface is cleaned with a neutralized argon ion beam at energies ranging from 50 to $500 \mathrm{eV}$ for 10 s. In situ a Ti/Pt/Au Schottky metallization is evaporated.

The diodes are characterized by $I-V$ measurements and the MESFETs by direct current and on-wafer high frequency $(\leqslant 40 \mathrm{GHz}) S$-parameter measurements. The results of these measurements are compared to a device whose top layer was removed wet chemically. The recovery of the damage is studied as function of the annealing temperature.

\section{RESULTS}

The reverse and forward $I-V$ characteristics of diodes processed at energies from 50 to $250 \mathrm{eV}$ with a neutralized argon beam are shown in Figs. 1 and 2, respectively. These

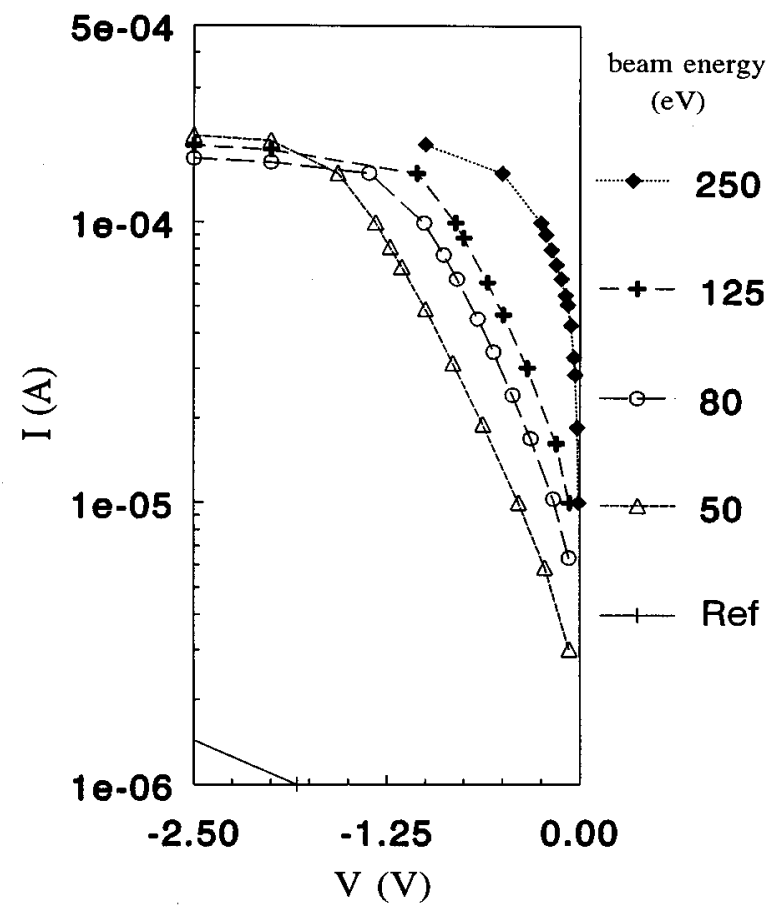

FIG. 1. The reverse $I-V$ characteristics of the diodes cleaned with a neutralized argon beam at different energies.

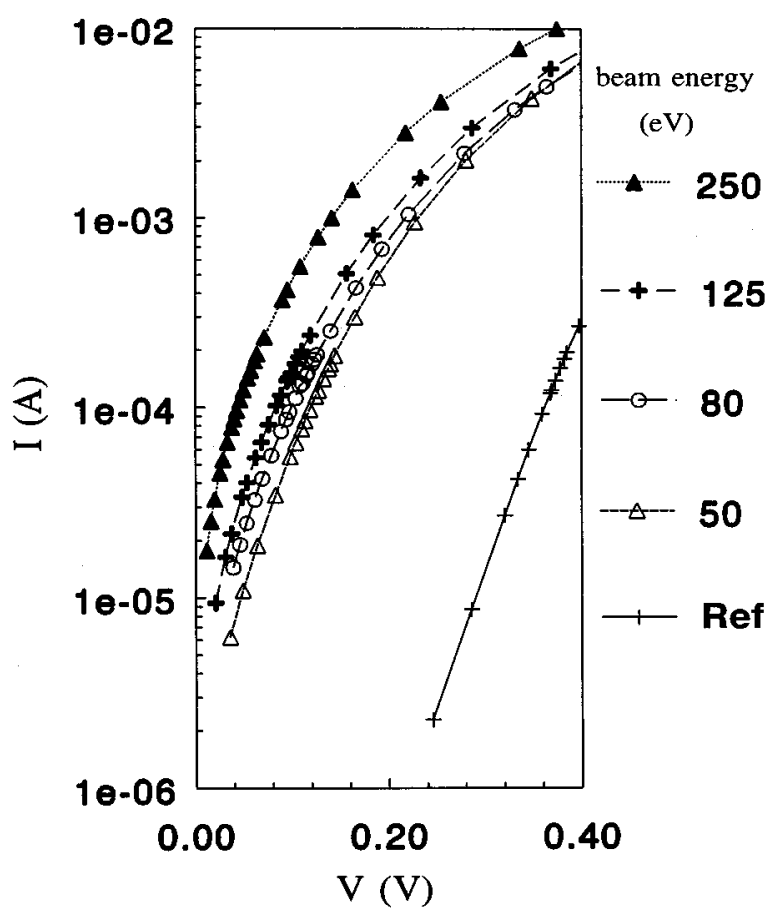

FIG. 2. The forward $I-V$ characteristics for diodes cleaned with a neutralized argon beam at energies up to $250 \mathrm{eV}$ compared to a reference diode.

characteristics are obtained prior to any heat treatment. The samples are compared to those which were cleaned in an ammonia solution. In both directions (forward and reverse) the performance degrades with increasing argon energy. Table II lists the parameters extracted from $I-V$ measurements of the in situ cleaned diodes before any heat treatment. These parameters are compared to a wet chemically cleaned diode. In comparison with the wet chemically cleaned diodes, the ideality factors $(n)$ of the argon-cleaned diodes are higher while the barrier heights $\left(\phi_{b}\right)$ are lower. The leakage current $I_{s}$ increases with increasing argon energy and is higher than that of the control sample. The breakdown voltage decreases (becomes less negative) with increasing energy and is much lower than the breakdown voltage of the control diode.

A heat treatment is performed to determine if this damage could be recovered. The diodes are treated at temperatures

TABLE II. The parameters extracted from the $I-V$ measurements on the diodes cleaned with a neutralized argon beam at different energies before annealing. The results are compared to a wet chemically cleaned control diode.

\begin{tabular}{ccccc}
\hline \hline $\begin{array}{c}\text { Energy } \\
(\mathrm{eV})\end{array}$ & $\begin{array}{c}\text { Ideality } \\
\text { factor } n\end{array}$ & $\begin{array}{c}\text { Barrier } \\
\text { height } \phi_{b} \\
(\mathrm{~V})\end{array}$ & $\begin{array}{c}\text { Leakage } \\
\text { current } I_{s} \\
(\mathrm{~A})\end{array}$ & $\begin{array}{c}\text { Breakdown } \\
\text { voltage } V_{\mathrm{br}} \\
(100 \mu \mathrm{A})\end{array}$ \\
\hline $\begin{array}{c}\text { Reference } \\
50\end{array}$ & 1.22 & 0.72 & $9 \times 10^{-10}$ & $<-8$ \\
80 & 1.57 & 0.52 & $4.8 \times 10^{-6}$ & -1.31 \\
125 & 1.47 & 0.51 & $6.8 \times 10^{-6}$ & -1.03 \\
250 & 1.38 & 0.50 & $8.9 \times 10^{-6}$ & -0.75 \\
500 & 1.42 & 0.47 & $3.1 \times 10^{-5}$ & -0.25 \\
\hline \hline
\end{tabular}




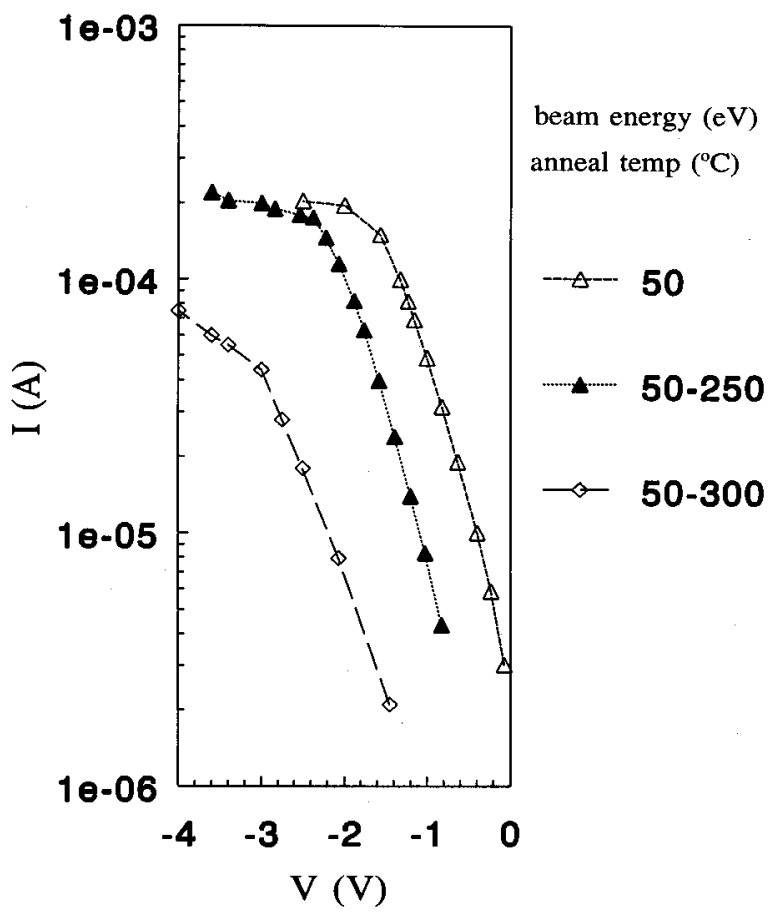

FIG. 3. The reverse $I-V$ characteristics of a diode cleaned with a neutralized argon ion beam at $50 \mathrm{eV}$, annealed at different temperatures.

ranging from 200 to $300{ }^{\circ} \mathrm{C}$ for $24 \mathrm{~h}$ in a nitrogen ambient. Above $300{ }^{\circ} \mathrm{C}$ the surface and the edges of the diodes and ohmic contacts deteriorate. Annealing at a temperature equal or less than $200{ }^{\circ} \mathrm{C}$ did not show any influence on the $I-V$ characteristics.

Figures 3 and 4 show the influence of annealing on the $I-V$ characteristics of diodes cleaned at $50 \mathrm{eV}$. The legends show, respectively, the energy of the neutralized argon beam and the annealing temperature. For $50 \mathrm{eV}$ the diodes showed an improvement in the forward and reverse characteristics with increasing annealing temperature. This is also observed using energies of 80 and $125 \mathrm{eV}$. The recovery is most remarkable on diodes cleaned at $50 \mathrm{eV}$ and annealed at a temperature of $300{ }^{\circ} \mathrm{C}$. In this case, the saturation current decreases nearly four decades and is even lower than the unannealed control diode, but comparable to the control sample after having a heat treatment at $250{ }^{\circ} \mathrm{C}$. No further improvement was observed for the control diode at $300{ }^{\circ} \mathrm{C}$. The forward and reverse $I-V$ characteristics of the diodes cleaned at energies of 80 and $125 \mathrm{eV}$ show the same tendency as the samples treated at $50 \mathrm{eV}$, although the recovery is less pronounced. Table III shows the influence of a heat

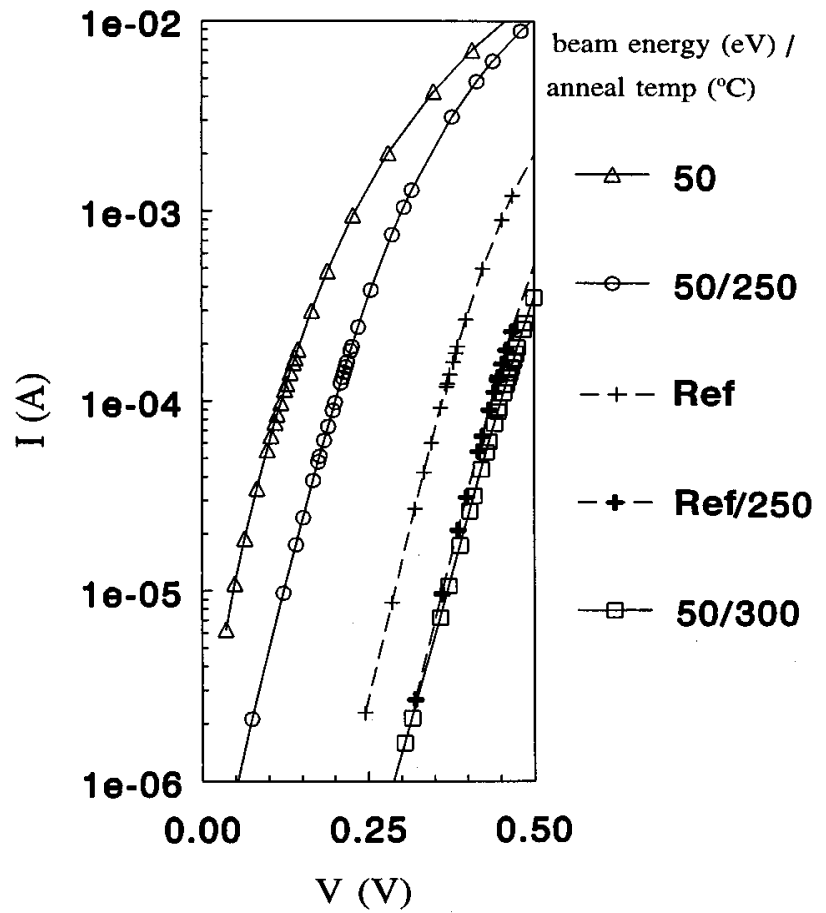

FIG. 4. The forward $I-V$ characteristics of a diode cleaned with a neutralized argon beam at $50 \mathrm{eV}$. The characteristics, annealed at different temperatures, are compared to a reference diode.

treatment on the ideality factor, the saturation current, and the barrier height for 50, 80, and $125 \mathrm{eV}$ compared to a reference diode. The ideality factor and the barrier height only have a significant change after processing at an energy of $50 \mathrm{eV}$. Despite the argon cleaning, no improved behavior could be observed after cleaning and annealing compared to the annealed reference diode.

At the lowest possible argon energy $(50 \mathrm{eV})$ the in situ argon cleaning time was varied in 10,20 , and $40 \mathrm{~s}$ in order to determine the dependence of the cleaning time. In comparison with the 10 s cleaning step, the $I-V$ characteristics and the extracted parameters did not change with the cleaning time.

The influence of a heat treatment on the diodes cleaned at higher energies is different from those cleaned with an energy less than $125 \mathrm{eV}$. Figure 5 shows the forward and the reverse $I-V$ characteristics of a diode cleaned at $250 \mathrm{eV}$. After annealing for $24 \mathrm{~h}$ at $200{ }^{\circ} \mathrm{C}$, the characteristics are nearly ohmic in the low bias range. The reverse characteristics degrade clearly with respect to the leakage current. Identical behavior is observed after cleaning at $500 \mathrm{eV}$. This

TABLE III. The influence of a heat treatment on the ideality factor $n$, the saturation current $I_{s}$, and the barrier height $\Phi_{b}$ of Schottky diodes. The diodes are cleaned with a neutralized argon beam. The parameters are compared to a reference diode.

\begin{tabular}{|c|c|c|c|c|c|c|c|c|c|c|}
\hline & \multicolumn{3}{|c|}{$\begin{array}{l}50 \mathrm{eV} \\
\text { heat treatment }\left({ }^{\circ} \mathrm{C}\right)\end{array}$} & \multicolumn{3}{|c|}{$\begin{array}{l}80 \mathrm{eV} \\
\text { heat treatment }\left({ }^{\circ} \mathrm{C}\right)\end{array}$} & \multicolumn{2}{|c|}{$\begin{array}{l}125 \mathrm{eV} \\
\text { heat treatment }\left({ }^{\circ} \mathrm{C}\right)\end{array}$} & \multicolumn{2}{|c|}{$\begin{array}{c}\text { Control } \\
\text { heat treatment }\left({ }^{\circ} \mathrm{C}\right)\end{array}$} \\
\hline & $\cdots$ & 250 & 300 & $\cdots$ & 250 & 300 & $\cdots$ & 300 & $\cdots$ & 250 \\
\hline$n$ & 1.57 & 1.45 & 1.47 & 1.48 & 1.47 & 1.47 & 1.37 & 1.58 & 1.22 & 1.27 \\
\hline$I_{s}(\mathrm{~A})$ & $4.8 \times 10^{-6}$ & $4.1 \times 10^{-7}$ & $5.0 \times 10^{-10}$ & $6.8 \times 10^{-6}$ & $2.0 \times 10^{-6}$ & $5.1 \times 10^{-7}$ & $8.9 \times 10^{-6}$ & $9.2 \times 10^{-7}$ & $9.0 \times 10^{-10}$ & $1.2 \times 10^{-10}$ \\
\hline$\phi_{b}(\mathrm{~V})$ & 0.52 & 0.58 & 0.75 & 0.51 & 0.54 & 0.58 & 0.50 & 0.56 & 0.72 & 0.79 \\
\hline
\end{tabular}




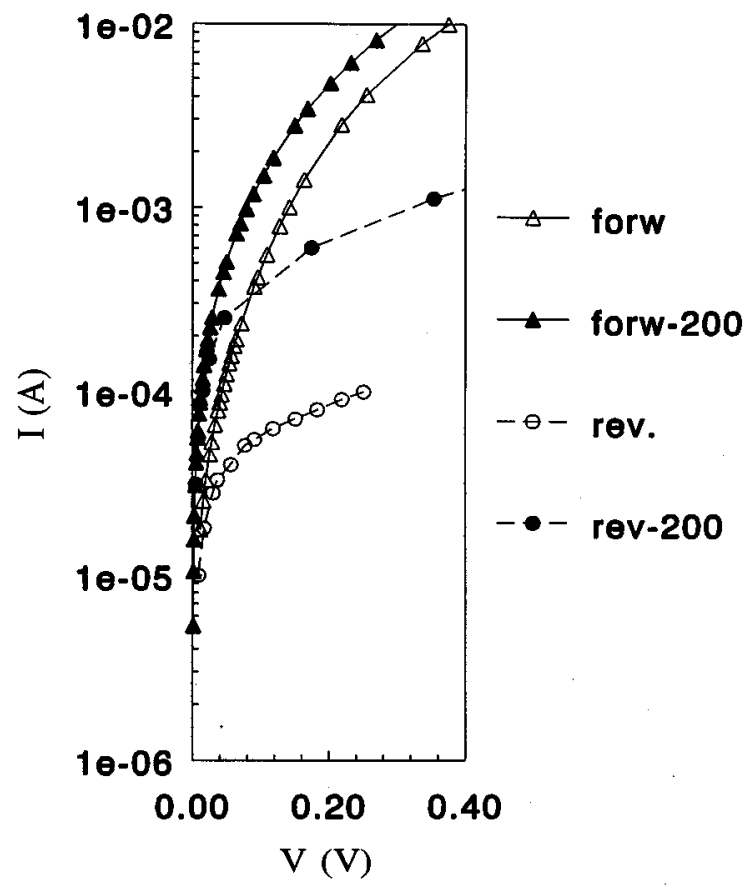

FIG. 5. The forward and the reverse $I-V$ characteristics of a diode cleaned at $250 \mathrm{eV}$ with a neutralized argon beam. The characteristics are shown before and after annealing at $200^{\circ} \mathrm{C}$.

means that at higher energies it is not possible to restore the damage created by the argon cleaning. It is therefore concluded that at higher energies the introduced damage becomes irreversible.

In addition to the influence of argon cleaning at different energies on Schottky diodes, the influence on the $I-V$ characteristics and on the $S$ parameters of MESFETs is determined. The same layer structure is used during these experiments. Before evaporation of the Schottky gate metallization and after the gate recess the GaAs surface is cleaned in situ with a $50 \mathrm{eV}$ neutralized argon beam. Figure 6 shows the $I_{\mathrm{ds}}-V_{\mathrm{gs}}$ and the transconductance $g_{m}$ of a MESFET with a gate length of $1.2 \mu \mathrm{m}$ and a gate width of $200 \mu \mathrm{m}$. The strongest influence is observed at a positive gate bias.

The transconductance increases remarkably after annealing at $300{ }^{\circ} \mathrm{C}$. This improvement of the transconductance is typical for all energies used during these experiments, even those energies at which the diodes become very leaky after a heat treatment $\left(\geqslant 250{ }^{\circ} \mathrm{C}\right)$. This probably means that the improvement is mainly initiated by a partial recovery of the active GaAs layer. Also, the channel current increases, which probably indicates a removal of an electron trapping mechanism. All the MESFETs measured showed the same behavior following ion cleaning and annealing.

$S$ parameters are measured on wafer between $45 \mathrm{MHz}$ and $40 \mathrm{GHz}$. For the high-frequency measurements the influence on the $S$ parameters is mainly observed for positive gate biases $V_{g}>0.3 \mathrm{~V}$. Changes in the $S$ parameters mainly occur at the input reflection coefficient $S_{11}$ and the transmission coefficient from input to the output $S_{21}$.

The current gain, deduced from the $S$ parameters at low frequencies, is increased from 8.1 to $10.6 \mathrm{~dB}$ as a conse-

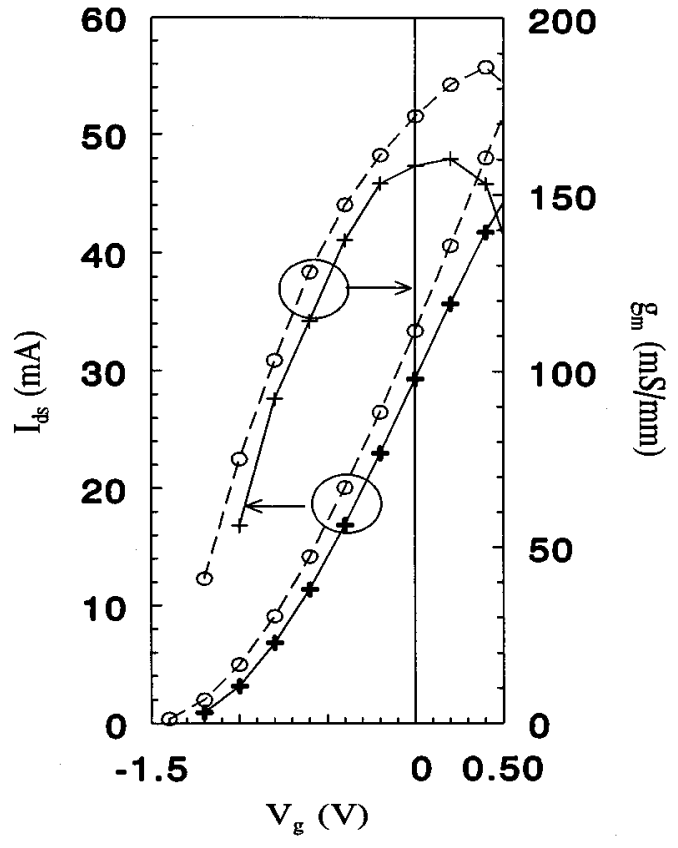

FIG. 6. The influence of argon cleaning with a neutralized beam at $50 \mathrm{eV}$ on the $I_{\mathrm{ds}}-V_{\mathrm{gs}}$ characteristics and the transconductance of a $1.2 \times 200 \mu \mathrm{m}$ MESFET before (+) and after annealing (0) at $300^{\circ} \mathrm{C}$ for $24 \mathrm{~h}$.

quence of annealing. The frequency of unity current gain $f_{t}$ is increased from 7.3 to $9.4 \mathrm{GHz}$. This is measured at a gate voltage of $0.6 \mathrm{~V}$. Below a gate voltage of $+0.4 \mathrm{~V}$ no difference in $f_{t}$ was observed. A circuit parameter extraction has been performed to study the influence of the argon treatment and annealing. The small-signal equivalent circuit is shown in Fig. 7. The parameter extraction fits well with the measured $S$ parameters by introducing a resistance $R_{\mathrm{gs}}$ parallel to the gate input capacitance $C_{\mathrm{gs}}$. This extra resistance is not necessary to fit a normally processed MESFET. In that case, the resistance can be neglected because of its high value (typically $>10^{7} \Omega$ ). The influence of annealing at $300^{\circ} \mathrm{C}$ on the channel resistance $R_{\mathrm{ds}}$ and on the parallel input resistance $R_{\mathrm{gs}}$ is very high. Upon annealing at $300{ }^{\circ} \mathrm{C}$ the parallel input resistance increased from 750 to $3060 \Omega$ and the drain-

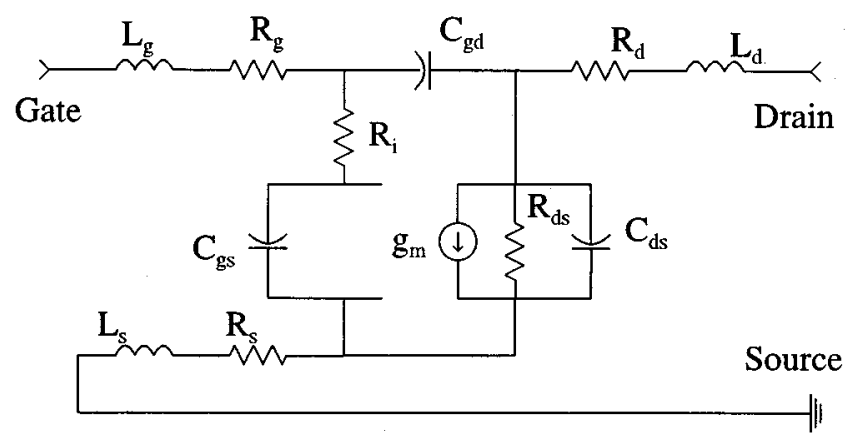

FIG. 7. The small-signal equivalent circuit used for the parameter extraction of the MESFETs. 
source resistance decreased from 445 to $360 \Omega$. This was measured at a gate voltage of $0.4 \mathrm{~V}$.

\section{DISCUSSION}

The $I-V$ characteristics of Schottky diodes after cleaning with a neutralized argon beam show a strong influence on the forward and reverse characteristics. The degradation increases with higher argon energies. Kwan et al. ${ }^{9}$ obtained comparable results on GaAs Schottky diodes. They explained the degradation by a preferential sputtering of arsenic atoms from the surface during argon cleaning. This arsenic depletion extends further into the material with higher energies. Full recovery of the diodes could not be achieved due to a gallium-rich surface. Walukiewicz ${ }^{13}$ ex- $^{-}$ plains the Fermi level pinning by defects which change their electrical characteristics depending on the position of the Fermi level (amphoteric native defects). He mainly considers Ga-rich surfaces by which a $\left(\mathrm{V}_{\mathrm{Ga}}+\mathrm{As}_{\mathrm{As}}\right)^{3-} \leftrightarrow\left(\mathrm{As}_{\mathrm{Ga}}+\mathrm{V}_{\mathrm{As}}\right)^{3+}$ transition is responsible for pinning the Fermi level between 0.5 and $0.7 \mathrm{eV}$ above the valence band. Here $V_{\mathrm{Ga}}$ is a gallium vacancy and the $\mathrm{As}_{\mathrm{Ga}}$ antisite is an arsenic atom on the gallium site. A similar approach can be obtained for arsenic-rich surfaces. The $\mathrm{As}_{\mathrm{Ga}}$ antisite is also considered by others as a cause of Fermi level pinning. ${ }^{14}$ This explains why the barrier height remained between 0.5 and $0.7 \mathrm{eV}$. Neffati ${ }^{9}$ showed by Schottky capacitance measurements that at low energies some additional interfacial states appeared. The shape of the barrier was greatly affected by the introduction of this interface charge.

Our results can be explained in a similar way. At low energies the disordered surface recovers and the $I-V$ characteristics improve after a heat treatment. At higher energies the defects are distributed upon annealing and a high degree of disorder occurs, which makes the $I-V$ characteristics worse. At $50 \mathrm{eV}$ the diodes are nearly full recovered. At 80 and $125 \mathrm{eV}$ the diodes recover only partially, and above 125 $\mathrm{eV}$ the rectifying behavior nearly disappears.

Compared to a wet chemically cleaned MESFET, the $I-V$ and microwave characteristics of a transistor treated with argon are worse. With respect to direct current measurements, the transconductance and the gate leakage current at positive gate bias become lower and higher, respectively, after performing a heat treatment. The threshold voltage decreases. After annealing the channel current increases, which probably indicates a removal of an enhanced electron trapping and consequently a reduction in the drain-source series resistance. The $S$ parameters show a change in the input reflection coefficient $\left(S_{11}\right)$ and the transmission coefficient from input to the output $\left(S_{21}\right)$. A parameter extraction with the smallsignal equivalent circuit could only be fitted if an additional resistance is included parallel to the gate input capacitance, which confirms the leaky behavior of the gate. In MESFETs fabricated without argon cleaning this resistance can be neglected because of its high value. Comparing the extracted circuit before and after annealing, the strongest influence is observed in the channel resistance and the parallel input resistance.

\section{CONCLUSIONS}

Damage in GaAs was observed after cleaning the surface with a neutralized argon beam by measuring the electrical characteristics of Schottky diodes. At the lowest energy of 50 $\mathrm{eV}$ least damage was obtained after annealing at $300^{\circ} \mathrm{C}$. For energies above $125 \mathrm{eV}$ the characteristics degraded upon annealing.

Despite the degradation of the diode characteristics at higher argon energies, the performance of MESFETs improved at all energies after annealing. This was explained by a partial recovery of the active GaAs layer. It is expected that improved results will be obtained at lower beam energies.

\section{ACKNOWLEDGMENTS}

The authors wish to thank W. van der Vleuten for supplying the MBE-grown layer structures and L. M. F. Kaufmann for his encouragement and helpful discussions.

${ }^{1}$ S. J. Pearton, U. K. Chakrabarti, and A. P. Perley, Mater. Res. Soc. Symp. Proc. 216, 507 (1991).

${ }^{2}$ F. D. Auret, G. Myburg, S. A. Goodman, L. J. Bredell, and W. O. Barnard, Nucl. Instrum. Methods B 67, 410 (1992).

${ }^{3}$ L. J. Bredell, F. D. Auret, G. Myburg, and W. O. Barnard, Appl. Surf. Sci. 50, 466 (1991).

${ }^{4}$ A. Vaseashta and L. C. Burton, Nucl. Instrum. Methods B 59/60, 1023 (1991).

${ }^{5}$ M. Kawabe, N. Kanzaki, K. Masuda, and S. Namba, Appl. Opt. 17, 2556 (1978).

${ }^{6}$ S. W. Pang, M. W. Geis, N. N. Efremow, and G. A. Lincoln, J. Vac. Sci. Technol. B 3, 398 (1985).

${ }^{7}$ C. L. Chen and K. D. Wise, IEEE Trans. Electron Devices ED-29, 1522 (1982).

${ }^{8}$ T. Neffati, G. N. Lu, and C. Barett, Solid-State Electron. 31, 1335 (1988).

${ }^{9}$ P. J. Smith and D. A. Allan, Vacuum 34, 209 (1983).

${ }^{10}$ P. Kwan, K. N. Bhat, J. M. Borrego, and S. K. Ghandi, Solid-State Electron. 26, 125 (1983).

${ }^{11}$ H. Hidaka, K. Akita, M. Taneya, and Y. Sugimoto, Electron. Lett. 26, 1112 (1990)

${ }^{12}$ K. L. Seaward and N. J. Mol, J. Vac. Sci. Technol. B 10, 46 (1992).

${ }^{13}$ W. Walukiewicz, J. Vac. Sci. Technol. B 5, 1062 (1987).

${ }^{14}$ W. E. Spicer et al., J. Vac. Sci. Technol. B 6, 1245 (1988). 